\title{
Is delamanid a potential agent in the treatment of diseases caused by Mycobacterium avium-intracellulare?
}

\begin{abstract}
To the Editor:
Delamanid, a new agent derived from the nitro-dihydro-imidazooxazole class of compounds that inhibits mycolic acid synthesis, has strong in vitro activity against Mycobacterium tuberculosis, including multidrug resistant (MDR) strains [1]. The drug has been proven to be effective in treatment of MDR tuberculosis (MDR-TB) patients [2-5]. Delamanid is pharmacologically characterised by an excellent intracellular bactericidal activity and a high accumulation rate [6].

It has been known for decades that for patients with pulmonary disease caused by Mycobacterium avium-intracellulare complex (MAC), the rates of failure, relapse, death and default are high [7]. Treatment options after failure of first-line drug combinations are poor and regimen with alternative drug combinations are not yet established [8]. Although scientific evidence for treatment concepts based upon drug susceptibility tests in vitro is not broad, such testing is recommended in case of treatment failure $[8,9]$.
\end{abstract}

Screening the new tuberculosis drugs, like delamanid (and bedaquiline), for activity against nontuberculous mycobacteria (NTM) was recently required $[10,11]$.

For decades, our laboratory routinely determines minimal inhibitory concentrations (MIC) of first- and second-line tuberculosis drugs in MDR-TB as well MAC and other NTM strains [12].

In order to evaluate a potential role of delamanid in the treatment of MAC disease, we tested 20 strains of MAC against the new compound. All samples were clinical isolates from patients with pulmonary disease treated at our centre between 2008 and 2015. MIC testing was performed with a modified agar dilution method on Middlebrook 7H10 agar as described elsewhere [13-15]. MIC was defined as the lowest drug concentration that inhibits at least $99 \%$ of the bacterial proportion after a two-fold serial dilution of the respective drug (MIC99).

Results are shown in table 1. MAC strains, among those single strains with high MIC against clarithromycin, exhibited low MIC against delamanid, varying from 0.013 to $0.4 \mu \mathrm{g} \cdot \mathrm{mL}^{-1}$. The MIC tend to be only slightly higher than those published about strains of M. tuberculosis [1]. To our knowledge, this is the first evidence that delamanid is a potential agent in the treatment of diseases caused by M. avium-intracellulare.

Thus, it seems worth it to evaluate delamanid in clinical studies on the treatment of patients who experience treatment failure of mycobacterial disease caused by MAC. In general, these diseases require a lengthy treatment. Therefore, a design for a clinical study of delamanid in a combination treatment of diseases caused by mycobacteria which are difficult to treat, such as MAC, should give consideration to an administration of delamanid longer than 6 months as approved for the treatment of MDR tuberculosis.

In view of the excellent intracellular accumulation of delamanid which achieves drug concentrations higher than the MIC we measured for MAC strains also with daily doses of $100 \mathrm{mg}$ [6], a study on a combination treatment of patients with refractory or recurrent MAC disease with a delamanid dosage lower than the recommended daily allowance for the treatment of MDR tuberculosis $(200 \mathrm{mg})$ should be discussed.

TABLE 1 Minimal inhibitory concentrations of delamanid against Mycobacterium avium-intracellulare complex strains

\begin{tabular}{lccccccc} 
& Strains $\mathrm{n}$ & \multicolumn{5}{c}{ Minimal inhibitory concentrations $\boldsymbol{\mu g} \cdot \mathrm{mL}^{-1}$} \\
\cline { 3 - 7 } & & $\mathbf{0 . 0 1 3}$ & $\mathbf{0 . 0 2 5}$ & $\mathbf{0 . 0 5}$ & $\mathbf{0 . 1}$ & $\mathbf{0 . 2}$ & $\mathbf{0 . 4}$ \\
\hline $\begin{array}{l}\text { Mycobacterium avium } \\
\text { Mycobacterium intracelullare }\end{array}$ & 9 & & 1 & & 3 & 5 & \\
\hline
\end{tabular}



strains http://ow.ly/xDiM304ul7O

David Krieger ${ }^{1}$, Nicolas Schönfeld ${ }^{1}$, Silvan Vesenbeckh ${ }^{1}$, Gudrun Bettermann ${ }^{2}$, Torsten Thomas Bauer ${ }^{1,3}$, Holger Rüssmann ${ }^{2}$ and Harald Mauch ${ }^{2}$

${ }^{1}$ Klinik für Pneumologie, Lungenklinik Heckeshorn, HELIOS Klinikum Emil von Behring, Berlin, Germany. ${ }^{2}$ Institut für Mikrobiologie, Immunologie und Laboratoriumsmedizin, HELIOS Klinikum Emil von Behring, Berlin, Germany.

${ }^{3}$ Deutsches Zentralkomitee zur Bekämpfung der Tuberkulose (DZK), Berlin, Germany.

Correspondence: David Krieger, Klinik für Pneumologie, Lungenklinik Heckeshorn, HELIOS Klinikum Emil von Behring, Walterhoeferstr. 11, 14165 Berlin, Germany. E-mail: david.krieger@helios-kliniken.de

Received: July 152016 | Accepted after revision: Sept 132016 | First published online: Nov 112016

Conflict of interest: None declared.

\title{
References
}

1 Matsumoto M, Hashizume H, Tomishige T, et al. OPC-67683, a nitro-dihydro-imidazooxazole derivative with promising action against tuberculosis in vitro and in mice. PLoS Med 2006; 3: e466.

2 Skripconoka V, Danilovits M, Pehme L, et al. Delamanid improves outcomes and reduces mortalitiy in multidrug-resistant tuberculosis. Eur Respir J 2013; 41: 1393-1400.

3 Sotgiu G, Pontali E, Centis R, et al. Delamanid (OPC-67683) for treatment of multi-drug-resistant tuberculosis. Expert Rev Anti Infect Ther 2015; 13: 305-315.

4 Tadolini M, Garcia-Prats AJ, D'Ambrosio L, et al. Compassionate use of new drugs in children and adolescents with multidrug-resistant and extensively drug-resistant tuberculosis: early experiences and challenges. Eur Respir J 2016; 48: 938-943.

5 Tadolini M, Lingtsang RD, Tiberi S, et al. First case of extensively drug-resistant tuberculosis treated with both delamanid and bedaquiline. Eur Respir J 2016; 48: 935-938.

6 Diacon AH, Dawson R, Hanekom M, et al. Early bactericidal activity of delamanid (OPC-67683) in smear-positive pulmonary tuberculosis patients. Int J Tuberc Lung Dis 2011; 15: 949-954.

7 Xu HB, Jiang RH, Li L. Treatment outcomes for Mycobacterium avium complex: a systematic review and meta-analysis. Eur J Clin Microbiol Infect Dis 2014; 33: 347-358.

8 Griffith DE, Aksamit T, Brown-Elliot BA, et al. An official ATS/IDSA statement: diagnosis, treatment, and prevention of nontuberculous mycobacterial diseases. Am J Respir Crit Care Med 2007; 175: 367-416.

9 Schönfeld N, Haas W, Richter E, et al. Recommendations for diagnosis and treatment of nontuberculous mycobacterioses of the German Central Committee against tuberculosis and the German Respiratory Society. Pneumologie 2013; 67: 605-633.

10 Raju RM, Raju SM, Zhao Y, et al. Leveraging advances in tuberculosis diagnosis and treatment to address nontuberculous mycobacterial disease. Emerg Infect Dis 2016; 22: 365-369.

11 Pontali E, Sotgiu G, D'Ambrosio L, et al. Bedaquiline and multidrug-resistant tuberculosis: a systematic and critical analysis of the evidence. Eur Respir J 2016; 47: 394-402.

12 Radenbach KL. Diagnostische und therapeutische Fortschritte bei nichttuberkulösen Mykobakteriosen [Diagnostic and therapeutic progress in nontuberculous mycobacterioses]. Prax Klin Pneumol 1985; 39: 43-49.

13 Schönfeld N, Bergmann T, Vesenbeckh S, et al. Minimal inhibitory concentrations of first-line drugs of multidrug-resistant tuberculosis isolates. Lung India 2012; 29: 309-312.

14 Kent PT, Kubica GP. Public health mycobacteriology: a guide for the level III laboratory. Atlanta, USDHHS, Centers for Disease Control, 1985.

15 McClatchy JK. Antimycobacterial drugs: mechanism of action, drug resistance, suscebtibilitiy testing and assays of activity in biological fluids. In: Lorian V, ed., Antibiotics in Laboratory Medicine, 2nd Edn. Baltimore, The Williams and Wilkins Co., 1986; pp. 181-222.

\section{Specific airway resistance in preschool children: why not panting after all?}

\author{
To the Editor:
}

Specific airway resistance (sRaw) is measured with minimal cooperation in the preschool child during tidal breathing [1]. Methodological difficulties have been encountered in modern plethysmographs when the warming and humidification of the inspired gas [2] are replaced by numerical algorithms to eliminate the thermo hygrometric artefact [1,3,4]. Measuring sRaw during panting [5] had been dismissed in preschool children based on the assumption that the ventilatory manoeuvre would be difficult to perform and 